\title{
O NOVO PNPG E A EDUCAC̣ÃO BÁSICA
}

Luciano Mendes de Faria Filho*

A pós-graduação brasileira, sobretudo a pública, é reconhecidamente o nível melhor avaliado da educação nacional. Há um razoável consenso de que as qualidades da pós-graduação estão diretamente relacionadas ao alto investimento feito ao longo dos últimos 40 anos, ou seja, desde o regime militar, tanto na sua infraestrutura quanto na formação e profissionalização dos pesquisadores - alunos e professores - que dela se ocupam. Relacionadas a esse alto investimento estão, sem dúvida, tanto a institucionalização de uma verdadeira cultura de avaliação desse nível da educação quanto as diversas tentativas de fazer o planejamento de seu crescimento e financiamento.

Ao longo dos anos, o que se observou é que a Capes enfatizou muito mais as políticas e práticas de avaliação da pós-graduação do que aquelas relacionadas ao seu planejamento. Isso, no entanto, não significou que essa última dimensão tenha ficada esquecida. Pelo contrário, a necessidade de planejar a pós-graduação sempre esteve na pauta das discussões da Capes e da comunidade científica nacional e disso os planos nacionais de pós-graduação são testemunhas importantes.

Atualizando e operacionalizando essa preocupação quanto ao planejamento, a Capes, após meses de preparação, publicou, no final de 2011, o novo plano nacional de pós-graduação referente ao período de 2011 a 2020. O documento traz um ousado e detalhado plano decenal daquilo que a agência considera fundamental para o crescimento e qualificação da pesquisa e a formação de recursos humanos de alto nível para fazer frente aos grandes desafios que se colocam para o país no período. Dentre os aspectos detalhados no plano merece destaque a inédita centralidade da relação entre a pós-graduação e a educação básica.

\footnotetext{
*Doutor em Educação pela Universidade de São Paulo (USP); Professor Titular da Faculdade de Educação da Universidade Federal de Minas Gerais (UFMG); Bolsista 1A de Produtividade em Pesquisa do CNPq; Coordenador do Projeto Pensar a Educação Pensar o Brasil. E-mail: luciano.mendes@pq.cnpq.br
} 
Quando a Capes publicou o documento contendo o Plano Nacional de Pós-Graduação 2011-2020, escrevi um texto para o Jornal da Ciência-JC, e-mail da SBPC, em que me posicionava sobre a forma como os responsáveis pelo documento entendiam a relação entre a pós-graduação e a educação básica no país ${ }^{1}$. Depois, publiquei outro artigo, no mesmo jornal, sobre a relação entre a pesquisa realizada na área de educação e a questão da qualidade da educação básica no país ${ }^{2}$. Como a Educação em Revista, em número recente (n. 28, v. 3), publicou um texto de dois colegas da UFMG - também responsáveis pela elaboração do Plano - sobre o assunto, achei por bem retomar aquelas reflexões anteriormente publicadas ${ }^{3}$.

O texto, é bom que se diga, faz uma síntese dos aspectos fundamentais do Plano e, como tal, não foca detidamente a educação. No entanto, quando o faz, é de maneira ligeira e bastante genérica, como ao dizer que

[...] a priorização, no quinto eixo, da educação básica e de outros níveis e modalidades de ensino, especialmente do ensino médio, dispensa maiores explicações e já foi elucidada: trata-se de uma ação emergencial, justificada pelo apagão do sistema de ensino nos níveis fundamental e médio. (p. 43).

No entanto, é preciso ressaltar que no Plano, de forma inédita, aparece todo um capítulo (o de número 8) dedicado à relação entre o sistema nacional de pós-graduação e a educação básica no país. Pelo teor do documento apresentado, não apenas a educação básica ganha grande centralidade na Capes, como já vinha acontecendo, mas também para os programas de pós-graduação.

Para construir o texto, a comissão, na qual não havia nenhum especialista em educação básica, busca dialogar com o documento da ABC e da Unesco e com documentos oficiais do MEC e do CNE, desconsiderando completamente a produção acumulada nas áreas de educação e ensino de ciências e matemática. Isso, talvez, ajude a entender a marcante presença de um verdadeiro "senso comum científico" sobre educação no Plano. Chama atenção, também, o tom por demais prescritivo do documento (deve... deve...), numa comissão que, como já se disse, não contava com nenhum especialista em educação para a discussão do tema.

De todo modo, o documento apresentado mapeia os grandes problemas da educação básica brasileira e, para resolvê-los, propõe estratégias 
e ações no âmbito do conjunto do sistema escolar e, mais especificamente, no âmbito da Capes. Como estratégia, o documento propõe:

A orientação é no sentido de que o desenvolvimento desse novo programa seja levado a cabo por uma equipe multidisciplinar, possibilitando, assim, o envolvimento de todos os cursos de pós-graduação e uma verdadeira ampliação do debate. Não ficando restrito, portanto, somente aos programas de pós-graduação em educação. (p. 164).

Tal perspectiva é reforçada, ao final do capítulo, quando, antes de elencar as ações que deverão ser levadas a cabo pela Capes, o documento reitera:

Os resultados alcançados pela educação básica ainda continuam abaixo do esperado. Por isso, esse é um momento do Sistema Nacional de Pós-Graduação adotar esse tema como estratégico e estudá-lo de uma forma integral, envolvendo todas as áreas do conhecimento. (p. 177).

Finalmente, o PNPG afirma que, levando em conta a estratégia acima anunciada, a Capes deveria desenvolver um conjunto de ações voltadas para a produção do conhecimento sobre educação básica, contribuindo assim para a valorização dos professores e para a formação docente.

No seu conjunto, o novo PNPG proposto e aprovado reafirma, sem dúvida, a importância da educação básica para o desenvolvimento social, econômico e tecnológico do país, reconhecendo também que não dá mais para sustentar um Sistema Nacional de Pós-Graduação de primeiro mundo com uma escola básica em que a valorização do professor e as condições de trabalho aproximam-se do quarto mundo.

Por outro lado, para o PNPG é imperativo que as outras áreas - além da área da educação - se preocupem com a educação básica. Aliás, há que se reconhecer que depois que a Capes passou a dispor de mais recursos para a educação básica, várias áreas, instituições e pesquisadores passaram a propor ações em educação. O problema, parece-me, é que muitas dessas ações, assim como o próprio texto do PNPG, não tomam o conhecimento produzido nos programas em educação e em ensino de ciências e matemática importante como ferramentas para atuarem. Por outro lado, não são poucos os pesquisadores da área de educação e de ensino de ciências e matemática que se admiram desse repentino interesse das outras áreas pela educação 
básica quando, no cotidiano de nossas universidades, esse interesse não parece existir.

De todo modo, a estratégia delineada pelo PNPG pode ser um bom motivo para as instituições científicas e a acadêmicas - SBPC, instituições representativas das diversas áreas do conhecimento, CAs da Capes e do CNPq - encontrarem-se para discutir quais as melhores formas de operacionalizar as ações postas como prioritárias no Plano. Terão esses grupos a capacidade de superar as mútuas desconfianças e desenvolver ações conjuntas visando à melhoria da educação básica brasileira? Esse é, a meu ver, o grande desafio!

\section{A PESQUISA EM EDUCAC̦ÃO E A QUALIDADE DA ESCOLA BÁSICA}

Nessa mesma linha de raciocínio, quando se fala da relação da pós-graduação com a educação básica, é muito comum ouvirmos, mesmo de colegas do CNPq e da Capes, a indagação de como é possível termos uma pós-graduação e pesquisas de excelência na área e, ao mesmo tempo, uma escola básica de qualidade muito discutível. O argumento por trás dessa indagação quase sempre é que a pesquisa na área, apesar de abundante e qualificada, não impacta a qualidade da escola pública brasileira.

De fato, a comunidade de pesquisa em educação é a maior comunidade científica do país, segundo os dados do Diretório dos Grupos de Pesquisa do CNPq: ela reúne mais de 5.500 doutores, mais de 3 mil professores em programas de pós-graduação das áreas de educação e ensino de ciências e matemática e algumas dezenas de milhares de alunos de mestrado e doutorado.

Mas é preciso perguntar: seria correta (e justa) a ideia de que a pesquisa que fazemos não impacta a qualidade da escola pública? Parece-me que não. Talvez, para efeitos de comparação, poderíamos perguntar também: será que a pesquisa na área médica não impacta a saúde pública no Brasil? $\mathrm{E}$ aquelas das áreas das engenharias, não têm impacto na qualidade das estradas ou do trânsito no país? Como se vê, se tomarmos esses rumos muitas seriam as áreas cujas pesquisas ficariam em suspeição a respeito de sua contribuição à melhoria dos serviços públicos que lhes são afetos. Mas não me parece que o caminho seja esse. 
Em primeiro lugar, um olhar mais apurado nos permitiria ver que muitas das melhores políticas de educação desenvolvidas nos diversos níveis da administração pública - da educação infantil ao ensino superior - têm por base os conhecimentos produzidos e acumulados nas últimas décadas nos programas de pós-graduação em educação e de ensino de ciências e matemática. Dentre os inúmeros exemplos que poderíamos citar está, com certeza, a política nacional do livro didático destinado às séries iniciais. Quem não reconhecer, hoje, o salto de qualidade que se deu nessa política pública de educação que atinge milhões de alunos é porque não se deu ao trabalho de comparar a qualidade dos livros didáticos brasileiros de hoje com aqueles de algumas décadas anteriores. A esse respeito, está em elaboração um livro que mapeia as contribuições da pesquisa em educação à elevação da qualidade da escola pública no Brasil, demonstrando, inclusive, os fatores que facilitam e, no mais das vezes, dificultam que tais contribuições sejam generalizadas para as diversas redes de ensino.

Em segundo lugar, analisando a história do Brasil, nossa cultura política e as políticas educacionais que aqui se desenvolvem desde pelo menos o nascimento do Império, no século XIX, não deveria surpreender-nos o fato de termos uma ótima pós-graduação (para poucos) e uma escola pública básica cuja qualidade todos criticamos (para muitos). Ou seja, essa situação reflete, de maneira transparente, o que é o Brasil! Ou não?

Parece-me mais correto e honesto nos perguntarmos sobre os fatores intervenientes que impedem que os conhecimentos produzidos pelas pesquisas na área de educação e as boas experiências conduzidas em parceria entre pesquisadores e escolas tenham um maior impacto nas escolas básicas de todo o Brasil. Boa parte das razões que dificultam às pesquisas impactarem mais fortemente a qualidade da escola básica está, como se evidencia continuamente, no âmbito das políticas públicas para a área. É aí, nesse terreno em que os pesquisadores têm pouca ingerência ou capacidade de intervenção que se decide a sorte da escola pública brasileira. Nesse terreno também são bem conhecidos os grandes problemas enfrentados pelas escolas e não cabe aqui repeti-los.

Ou seja: definitivamente não é por falta de conhecimento que a nossa escola pública não é de melhor qualidade. O que já sabemos, hoje, sobre a escola, os processos de ensino e aprendizagem, a gestão e as demais dimensões que compõem e estruturam essa complexa instituição que é a 
escola, é muito mais do que suficiente para darmos um salto de qualidade em nossas escolas públicas. Uma contribuição fundamental dos pesquisadores da educação, em parceria com os professores da escola básica e ativistas sociais, foi, justamente, tornar esse conhecimento um senso comum crítico sobre a escola brasileira.

A educação escolar é um assunto complexo e é uma irresponsabilidade pública achar que ela pode ser conduzida por amadores e/ou por quem não conhece minimante as teorias básicas que dão suporte à intervenção pedagógica. Tal posição significa que é preciso tratar a pesquisa e os pesquisadores da área de educação com mais respeito e consideração, reconhecendo não apenas a complexidade dos temas que abordam e a sua expressiva contribuição para a produção do conhecimento sobre os fenômenos educativos. Passar da pesquisa e da produção do conhecimento à política é uma tarefa que, como sabemos, quase nunca depende do pesquisador e da qualidade do conhecimento que ele possui. Por isto, responsabilizar o pesquisador em educação pela qualidade da escola pública é ingenuidade ou, pior ainda, má-fé que esconde interesses inconfessáveis. 


\section{NOTAS}

${ }^{1}$ FARIAS FILHO, L. M. O novo PNPG e a educação básica. Jornal da Ciência, Rio de Janeiro, 23 set. 2011. E-mail: 4350. Disponível em: <www.jornaldaciencia.org.br/Detalhe. jsp?id $=79408>$.

${ }^{2}$ FARIAS FILHO, L. M. A pesquisa em educação e a qualidade da escola básica. Jornal da Ciência, Rio de Janeiro, 16 jun. 2011. E-mail: 4281. Disponível em: <www.jornaldaciencia. org.br/Detalhe.jsp?id=78016>.

3 BARRETO, F. C. de S.; DOMINGUES, I. O PNPG 2011-2020: os desafios do país e o sistema nacional de pós-graduação. Educação em Revista, Belo Horizonte, v. 28, n. 3, p. 17-53, 2012. http://dx.doi.org/10.1590/S0102-46982012000300002

Recebido: 30/01/2013

Aprovado: 20/05/2013

Contato:

Universidade Federal de Minas Gerais Faculdade de Educação Departamento de Ciências Aplicadas à Educação

Av. Antônio Carlos, 6627, Pampulha CEP $31270-901$ Belo Horizonte, MG

Brasil 